\title{
Clasificación química y geotermométrica de sulfuros del depósito aurífero Mina Pilar (Greenstone Belt, Cuadrilátero Ferrífero, Brasil)
}

\author{
Johanna Ríos-Guerrero $^{1 *} \mathbb{D}$; Carlos Andrés Ballesteros-Camaro ${ }^{1}$ \\ Forma de citar: Ríos-Guerrero, J.; Ballesteros-Camaro, C.A. (2021). Clasificación química y geotermométrica \\ de sulfuros del depósito aurífero Mina Pilar (Greenstone Belt, Cuadrilátero Ferrífero, Brasil). Boletín de \\ Geología, 43(1), 147-161. https://doi.org/10.18273/revbol.v43n1-2021007
}

\begin{abstract}
Resumen
El Cuadrilátero Ferrífero es ampliamente conocido por sus depósitos de oro de clase mundial de edades arcaicas, clasificados principalmente como de tipo oro orogénico y epigenético. Estos depósitos están hospedados en una secuencia de rocas meta-volcanosedimentarias del grupo Nova Lima, principalmente en la Formación Ferrífera Bandeada (BIF), fuertemente sulfurada con pirita \pm pirrotita \pm arsenopirita \pm calcopirita $+\mathrm{Au}$, donde los cuerpos mineralizados se encuentran controlados por estructuras regionales con orientación NE y vergencia NW, asociados a alteraciones hidrotermales que exhiben zonación lateral. En el depósito pilar, el oro se encuentra diseminado en la Formación Ferrífera Bandeada y como oro libre en venas de cuarzo + carbonato asociado a los sulfuros, principalmente a la arsenopirita. Los principales sulfuros corresponden a pirrotita, pirita, calcopirita y arsenopirita, orientados según la foliación milonítica $\mathrm{S}_{3}$ en las rocas. Las asociaciones minerales que caracterizan a los halos de alteración hidrotermal son distribuidas según la posición de los cuerpos mineralizados, denominados como zona de cloritización (distal), carbonatización (intermedia) y sericitización (proximal). Las características de las composiciones químicas de los sulfuros relacionados a las fases minerales hidrotermales fueron realizadas a partir de los resultados obtenidos por análisis de microsonda electrónica. Los procesos hidrotermales asociados con la formación de la mineralización, según la paragénesis de sulfuros (arsenopirita \pm pirrotita \pm pirita \pm oro (electrum)) revelan un equilibrio químico en el intervalo de temperatura entre $363^{\circ} \mathrm{C}$ hasta $471^{\circ} \mathrm{C}$.
\end{abstract}

Palabras clave: Cuadrilátero Ferrífero; Sulfuros; Química mineral; Geotermometría.

\section{Chemical classification and geothermometric of sulfides from the Pilar Mine gold deposit (Greenstone Belt, Quadrilátero Ferrífero, Brazil)}

\begin{abstract}
The Quadrilátero Ferrífero is widely known for its world-class epigenetic and orogenic gold deposits of Archean ages. These are hosted in a sequence of meta-volcano sedimentary rocks of the Nova Lima group, mainly with the Banded Ferriferous Formations (BIF) and strongly sulfured with pyrite \pm pyrrhotite \pm arsenopyrite \pm chalcopyrite $+\mathrm{Au}$, where many of the mineralized bodies are structurally controlled due to the influence of regional NE structures and related to strongly hydrothermal zones. At the Pilar deposit, gold is disseminated in the Banded Iron Formation sequences and as free gold in quartz + carbonate veins associated with sulphides, mainly arsenopyrite. The main sulphides correspond to pyrrhotite, pyrite, chalcopyrite, and arsenopyrite, oriented according to a mylonitic $\mathrm{S}_{3}$ foliation of the rocks. Three halos of hydrothermal alteration are identified, distributed according to the position of the mineralized bodies, being chloritization zone (distal), carbonatization (intermediate) and sericitization (proximal). Chemical compositions of the sulfides associated with the hydrothermal mineral phases were carried out from the results obtained by electron microprobe analysis. The hydrothermal processes associated with the formation of mineralization, according to the paragenesis of sulphides (arsenopyrite \pm pyrrhotite \pm pyrite \pm gold (electrum)) reveal a chemical equilibrium in the temperature range between $363^{\circ} \mathrm{C}$ to $471^{\circ} \mathrm{C}$.
\end{abstract}

Keywords: Quadrilátero Ferrífero; Sulphides; Mineral chemistry; Geothermometry.

\footnotetext{
${ }^{1}$ Programa de Pós-graduação em Geociências, Universidade Federal do Amazonas, Manaus, Brasil. (*) joharios@gmail.com, carlosandres140@hotmail.com
} 


\section{Introducción}

El Cuadrilátero Ferrífero (CF) es una importante provincia metalogénica de Brasil, ampliamente conocida por sus depósitos de oro de clase mundial. Estos depósitos se encuentran hospedados en rocas de edades arcaicas, descritas de base a techo como una secuencia meta-volcanosedimentaria del grupo Nova Lima, donde estos cuerpos mineralizados se encuentran controlados por estructuras regionales de fallamiento inverso, plegamiento y relacionados a zonas fuertemente hidrotermalizadas conocidas como "Lapa Seca" (Vieira, 1991). Otros depósitos como São Bento, Córrego do Sitio exhiben mineralizaciones más complejas geocronológicamente, presentando edades arcaicas y paleo proterozoicas.

En la literatura, la génesis de los depósitos de oro del CF ha sido atribuida a diferentes procesos geológicos como, eventos deformacionales, metamórficos, hidrotermales y/o magmáticos. Trabajos anteriores en el depósito Pilar se han realizado como una necesidad de estudiar la geometría de las zonas de alteración hidrotermal usando métodos de espectrometría de reflectancia (Passos, 1999), así como estudios de prospección, considerando las características del oro en el depósito, tales como aspectos texturales, tamaño, modo de ocurrencia, entre otros (Silva, 2007). Otros trabajos de investigación recientes consisten en estudiar la génesis y el control de la mineralización dentro del depósito aurífero Pilar, considerando la paragénesis y las características de las fases minerales relacionadas a la estructura de los cuerpos mineralizados (Ríos-Guerrero, 2016).

Por otro lado, varios autores en la literatura atribuyen la importancia de sulfuros para el completo entendimiento de procesos geológicos asociados a metalogénesis mediante la utilización de diferentes técnicas petromineralógicas y químicas (Boyle y Jonasson, 1973; Eilu y Groves, 2001; Le Vaillant et al., 2005; Groves et al., 1998), en donde para el área de interés no se han abordado a detalle este tipo de estudios. Es por esto que, para el depósito Pilar y mineralizaciones asociadas al $\mathrm{CF}$, se hace importante el análisis de la composición química de estas fases minerales asociados a los diferentes procesos de metamorfismo, deformación y/o hidrotermalismo de la mineralización aurífera, que ayudan a determinar las condiciones de temperatura y génesis de los fluidos asociados a estos procesos.

\section{Localización de la mina Pilar}

La mina Pilar es una mina subterránea de oro en operación, con un área de aproximadamente 9.975 $\mathrm{km}^{2}$, localizada a $7 \mathrm{~km}$ del municipio de Santa Bárbara y a $93 \mathrm{~km}$ de Belo Horizonte, en el estado de Minas Gerais, Brasil (Figura 1). En conjunto con la mina de oro Roça Grande componen el complejo mineral Caeté. Este complejo está localizado entre los municipios de Caeté y Santa Bárbara, a $50 \mathrm{~km}$ al este de Belo Horizonte.

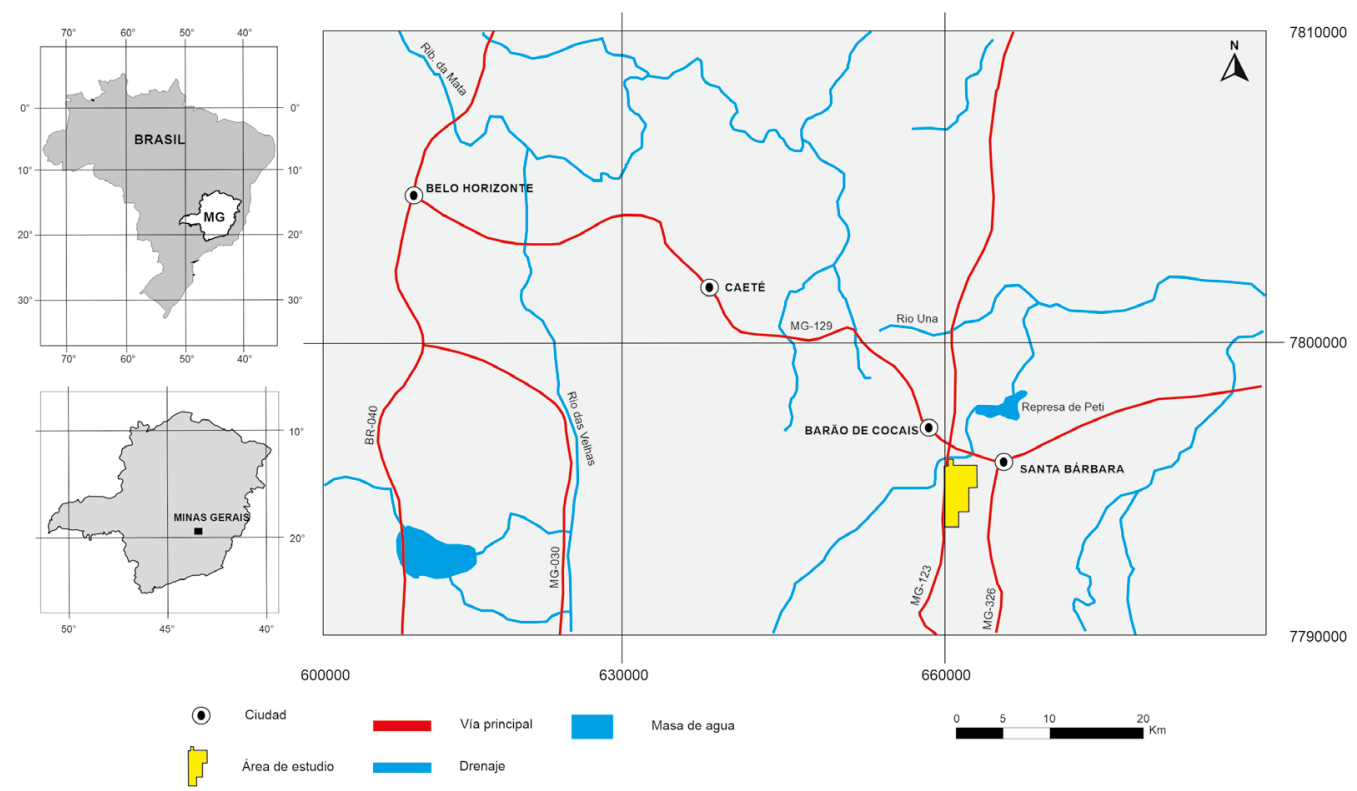

Figura 1. Mapa de localización del área de estudio con resalte en polígono amarillo con las principales vías de acceso y drenajes. En la izquierda el mapa de Brasil con destaque del estado de Minas Gerais. En la derecha destaque de la ciudad de Belo Horizonte (capital del estado) y los municipios de Caeté y Barão de Cocais. 


\section{Contexto Geológico}

\section{Geología regional}

El CF representa una provincia metalogénica $(\mathrm{Au}, \mathrm{Fe}$, Mn) del Precámbrico, localizada al suroeste del cratón São Francisco (Almeida y Hasui, 1984). Esta región es conocida como uno de los más importantes distritos auríferos de Brasil.

El CF está dividido en cuatro (4) unidades litoestratigráficas arcaicas - paleo proterozoicas: i) complejos metamórficos arcaicos compuestos por gneises, migmatitas y granitoides; ii) Supergrupo Rio das Velhas (SGRV) de edad arcaica, formada por rocas metasedimentarias y meta-volcánicas de bajo a medio grado de metamorfismo; iii) supergrupo Minas (Neo Arcaico - Paleo Proterozoico) compuesto por rocas metasedimentarias de alto a medio grado de metamorfismo; iv) Grupo Itacolomi (Paleo Proterozoico) compuesto de meta-arenitas y conglomerados. El CF también incluye pequeños cuerpos y venas pegmatíticas que cortan las capas más nuevas del supergrupo Minas, así como también generaciones de diques máficos que muestran los contrastes de los grados metamórficos (Noce y Machado, 1998; Baltazar y Zucchetti, 2007; Farina et al., 2016).

La región del $\mathrm{CF}$ y sus áreas adyacentes presentan una historia geotectónica compleja, que abarcan varios eventos deformacionales en regímenes dúctiles y/o frágiles. Estos terrenos fueron afectados por el Evento Trans Amazónico y las porciones al este del CF fueron intensamente retrabajadas durante el Evento Brasiliano (Teixeira, 1985). El CF es caracterizado por tres (3) conjuntos principales de estructuras que afectaron el SGRV y al Grupo Minas (Marshak et al., 1992; Alkmim y Marshak, 1998), descritas como: i) estructuras regionales con trend NE y vergencia NW, definido en estructuras de tipo pliegue y cabalgamiento que generaron sinclinales asimétricos; ii) estructuras extensionales relacionadas con la formación de la geometría de domos en las rocas deformadas y metamorfoseadas alrededor del basamento Arcaico.

\section{Geología del depósito Pilar}

El depósito Pilar se encuentra localizado en la parte nordeste del CF, el cual presenta características litológicas semejantes a otros depósitos de la zona, pero con una complejidad estructural e hidrotermal producto de la afectación intensa de eventos tectonometamórficos sobreimpuestos (Figura 2) (RíosGuerrero, 2016).
Se encuentra hospedado en una secuencia supracrustal del Greenstone Belt Rio das Velhas (Figura 3A), descrita estratigráficamente de base a techo: i) grupo Quebra Osso (Schorscher, 1978), el cual es constituido por esquistos talcosos; ii) grupo Nova Lima conformado por las unidades Ouro Fino con esquisto carbonato-albita-clorita-cuarzo, Morro Vermelho de esquisto cuarzo-clorítico y Santa Quitéria de esquisto carbonoso y, como parte superior de esta secuencia, la Formación Ferrífera Bandeada (BIF; Figura 3B). Estas unidades fueron deformadas y metamorfoseadas en facies esquisto verde, intruidas por diques máficos y entrecortadas por venas de cuarzo (Ríos-Guerrero, 2016).

Tectónicamente, este depósito se encuentra en una estructura de tipo pliegue isoclinal invertido con eje variable en el plano NE-SW $\left(050^{\circ} / 70^{\circ}\right)$, limitado por zonas de cizallamiento $\left(027^{\circ} / 50^{\circ}\right)$ y fallamiento inverso $\left(033^{\circ} / 50^{\circ}\right)$, que cortan las unidades del supergrupo Rio das Velhas, donde los cuerpos mineralizados se disponen en un plano paralelo a las estructuras principales, en la dirección NE-SW. Los principales cuerpos con mineralización se presentan como una serie de lentes tabulares sub paralelos y orientados $015^{\circ}$ con buzamiento de $65^{\circ}$, y localizados al este de la falla São Jorge (Ríos-Guerrero, 2016).

La mineralización aurífera se presenta de dos tipos; i) diseminada en el BIF asociado a los sulfuros de arsenopirita y pirrotita, dispuesta en la zona de charnela del pliegue y asociada a la zona de cizallamiento; ii) como oro libre en venas de cuarzo \pm carbonato (RíosGuerrero, 2016).

Estas rocas fueron afectadas por procesos tectonometamórficos asociados a tres posibles fases deformacionales; i) $\mathrm{D}_{1}$, caracterizado por un pliegue de tipo isoclinal, con desarrollo de la foliación $\mathrm{S}_{1}$; ii) $\mathrm{D}_{2}$, que generó deformación por zonas de cizallamiento con crenulación $\left(\mathrm{S}_{2}\right)$ de la foliación $\mathrm{S}_{1}$ y foliación milonítica $\mathrm{S}_{3}$, e interacción de fluidos hidrotermales con las rocas hospederas, además de la depositación de la mineralización de oro y venas de cuarzo \pm carbonato; iii) $\mathrm{D}_{3}$, asociado a un sistema de fallamiento paralelo a la zona de cizallamiento que generó fracturamiento y posterior relleno de venas sin mineralización (RíosGuerrero, 2016).

La interacción de fluidos de $\mathrm{H}_{2} \mathrm{O}, \mathrm{CO}_{2}, \mathrm{Fe}, \mathrm{SiO}_{2}, \mathrm{~S}$ y As con las diferentes litologías, proporcionaron la hidratación y el enriquecimiento en Fe de los diferentes minerales, lo cual generó halos de alteración 
hidrotermal, distribuidos según su proximidad a los cuerpos mineralizados y su principal mineral característico. Estos halos son descritos como zona de alteración distal o zona de cloritización, zona de alteración intermedia o zona de carbonatación y zona de alteración proximal o zona de sericitación (RíosGuerrero, 2016).

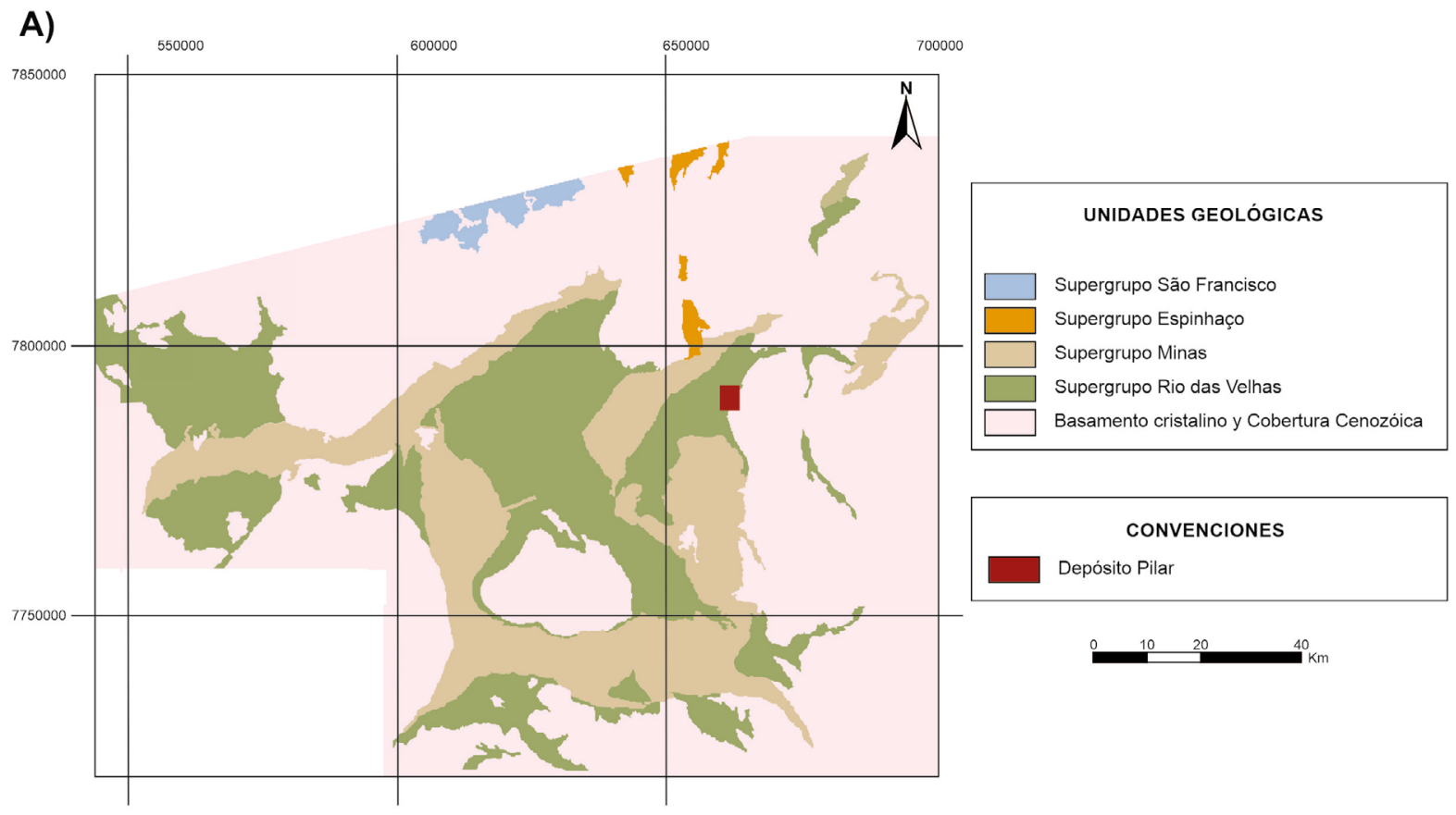

B)
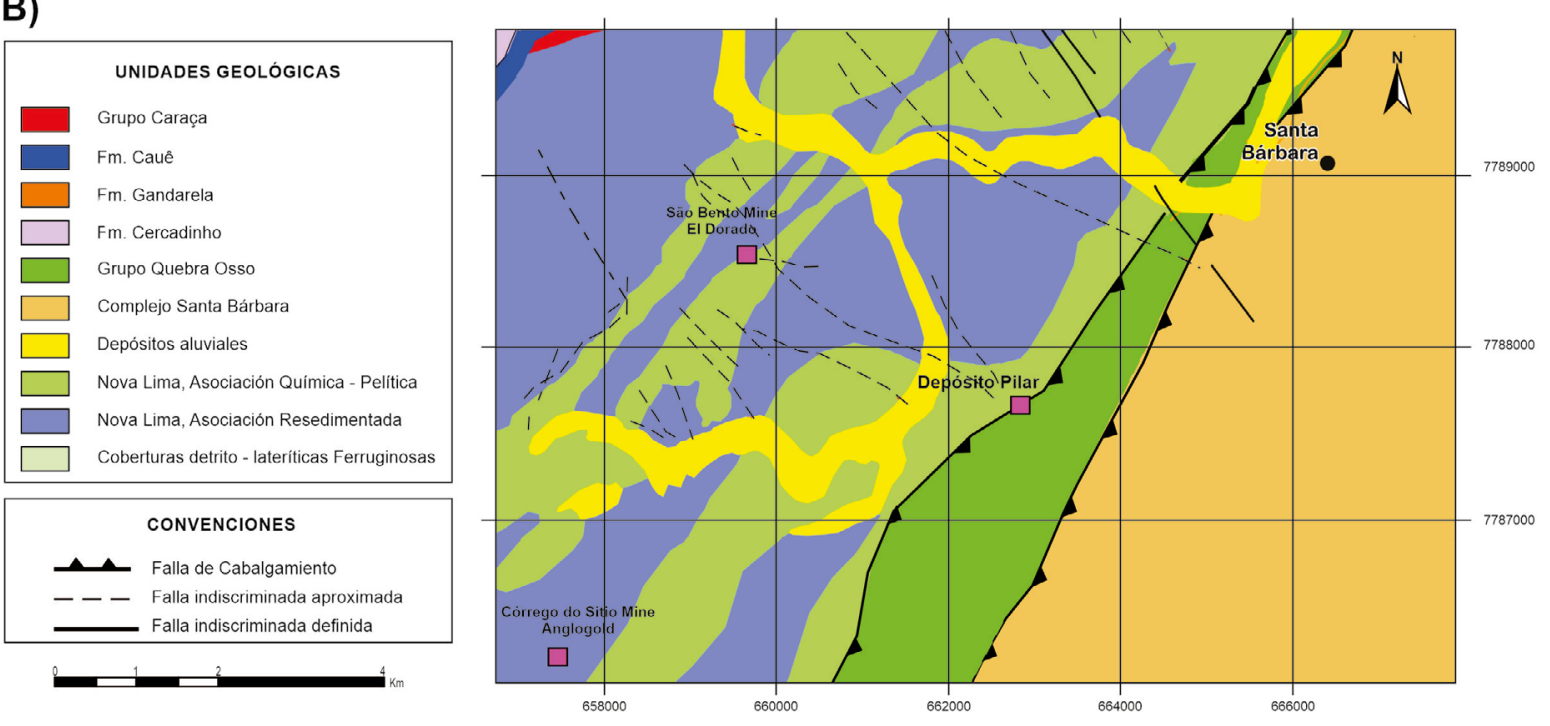

Figura 2. Litoestratigrafía del Cuadrilátero Ferrífero y área de estudio. A. Mapa geológico regional indicando el área de estudio. B. Mapa geológico del depósito Pilar (Silva, 2007). 

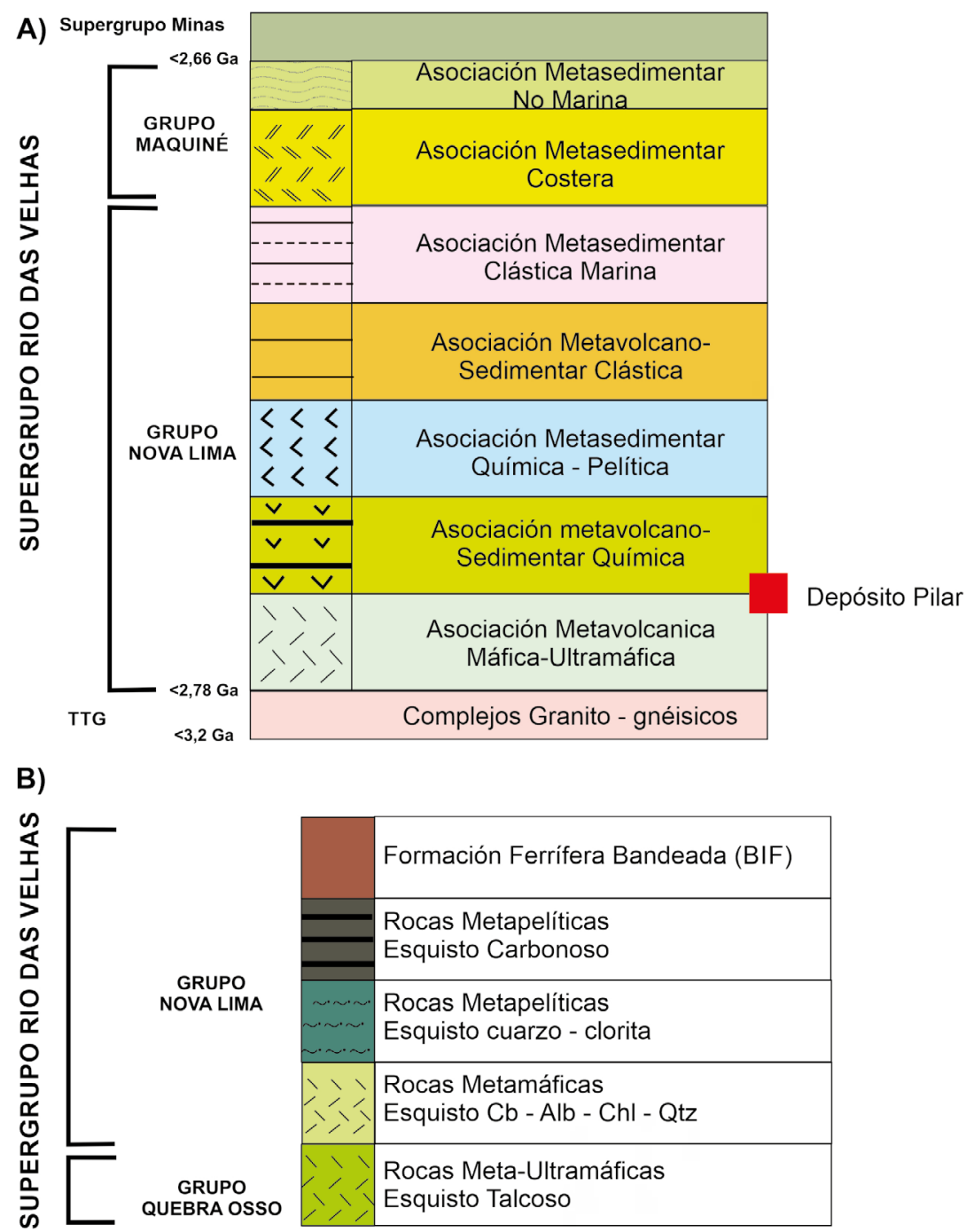

Figura 3. Columnas estratigráficas generalizadas. A. Columna estratigráfica idealizada para el supergrupo Rio das Velhas (Baltazar y Zucchetti, 2007). B. Representación esquemática de la columna estratigráfica para el depósito Pilar (Ríos-Guerrero, 2016).

\section{Metodología}

El trabajo de campo y de laboratorio, con reconocimientos de datos estructurales como foliaciones, fallas y venas en las unidades de roca de los niveles subterráneos N2, N3, N5, N6, N7 y de las zonas denominadas como cuerpos $\mathrm{C}$, BA, $\mathrm{BF}$ y BFII de la mina Pilar, fue realizado en varias etapas que incluyeron la descripción macroscópica y microscópica de las diferentes litologías, con principal énfasis en aquellas que presentan la mineralización y la alteración hidrotermal.
Fueron realizados 400 análisis, distribuidos en 20 láminas delgadas-pulidas representativas de zonas de alteración, las cuales fueron seleccionadas a partir de estudios petrográficos realizados en un microscopio petrográfico de marca Olympus, modelo BX51, del laboratorio de microscopia del programa de posgrado en geociencias (PPGEO) de la Universidad Federal del Amazonas (UFAM).

Los análisis de química mineral determinaron las variaciones composicionales en los sulfuros, además de posibilitar los cálculos de temperatura 
de la alteración hidrotermal asociada al evento mineralizador. Los análisis fueron realizados en el laboratorio de Microsonda Electrónica del Instituto de Geociencias de la Universidad de Brasilia (UnB), con un equipo JEOL JXA-8230, con 5 espectrómetros WDS (Wavelength-dispersive X-Ray Spectroscopy) y un EDS (Energy Dispersive X-Ray Spectroscopy). Los cristales analizadores disponibles (TAP, LIF, PETJ, LDE1, LIFH y PETH), permitieron que fueran analizados todos los elementos químicos con número atómico superior a cuatro (boro). Las condiciones operacionales usadas durante las rutinas fueron llevadas a cabo usando un voltaje de $20 \mathrm{kV}$ y una corriente de $20 \mathrm{nA}$, con un haz de electrones de $1 \mu \mathrm{m}$ de diámetro, tiempo de conteo de $10 \mathrm{~s}$ para cada elemento y $5 \mathrm{~s}$ de backgrounds inferior y superior. Cada elemento fue estandarizado usando minerales sintéticos y naturales. Los estándares y límites de detección (ppm) para los elementos analizados en la microsonda electrónica están en la Tabla 1.

Tabla 1. Estándar y límites de detección para los elementos analizados en microsonda electrónica. Lím: límite; Detec.= detección.

\begin{tabular}{cccccc}
\hline Elemento & Estándar & $\begin{array}{c}\text { Lím. Detec. } \\
(\mathbf{p p m})\end{array}$ & Elemento & Estándar & $\begin{array}{c}\text { Lím. Detec. } \\
\text { (ppm) }\end{array}$ \\
\hline $\mathrm{As}$ & $\mathrm{AsGa}$ & 220 & $\mathrm{Fe}$ & $\mathrm{CuFeS}_{2}$ & 260 \\
$\mathrm{Zn}$ & $\mathrm{ZnS}$ & 200 & $\mathrm{Co}$ & $\mathrm{Co}$ & 150 \\
$\mathrm{Ga}$ & $\mathrm{AsGa}$ & 200 & $\mathrm{Cu}$ & $\mathrm{CuFeS}_{2}$ & 240 \\
$\mathrm{Se}$ & $\mathrm{ZnSe}$ & 190 & $\mathrm{Ni}$ & $\mathrm{Ni}$ & 130 \\
$\mathrm{~S}$ & $\mathrm{Pirita}$ & 130 & $\mathrm{Mo}$ & $\mathrm{Mo}$ & 130 \\
$\mathrm{~Pb}$ & $\mathrm{PbS}$ & 220 & $\mathrm{Au}$ & $\mathrm{Au}$ & 150 \\
$\mathrm{Bi}$ & $\mathrm{Bi}$ & 220 & $\mathrm{Ag}$ & $\mathrm{Ag}$ & 70 \\
$\mathrm{Cd}$ & $\mathrm{Cd}$ & 120 & & & \\
\hline
\end{tabular}

Para determinar con precisión la composición de la arsenopirita, se consideraron los resultados obtenidos por Kretschmar y Scott (1976), donde se reportan algunos estándares mínimos para realizar análisis en microsonda electrónica. En este trabajo se consideran los diferentes productos de reacción, la naturaleza de los cristales y las texturas de intercrecimiento. Muchas de estas reacciones generan productos con porosidad (agregados multicristales mezclados con fluidos enriquecidos con $\mathrm{S}-\mathrm{As}$ ), por lo cual se consideran los siguientes criterios: i) los análisis deben realizarse principalmente en cristales bien formados $\mathrm{y}$, de no ser posible, estos deben sumar entre 98 y $101 \%$ peso (wt.\%); ii) cada análisis debe constar con un tiempo de conteo mínimo de $10 \mathrm{~s}$; iii) el \% atómico (at.\%) de Fe indica la calidad de los análisis, este puede variar entre 30,3 a 35,5 at.\%, dependiendo de la relación S/As de la arsenopirita.

Para el cálculo de temperatura de la paragénesis principal de los sulfuros, fue implementado el geotermómetro de la arsenopirita de Kretschmar y Scott (1976), que proponen un diagrama de concentración atómica de As vs Temperatura. Este geotermómetro permite determinar la formación de esta fase mineral, considerando que; i) la arsenopirita debe estar en equilibrio con otra asociación de sulfuros; ii) la concentración de elementos como el $\mathrm{Co}, \mathrm{Sb}$ y el Ni deben ser inferior a $1 \mathrm{wt}$ \% \% y iii) la arsenopirita debe formarse a temperaturas superiores a $300^{\circ} \mathrm{C}$.

\section{Resultados}

\section{Petrografía de fases opacas}

Los principales sulfuros encontrados fueron arsenopirita, pirrotita, pirita y calcopirita. Los minerales que acompañan el mineral aurífero se presentan orientados según la foliación milonítica $\mathrm{S}_{3}$, la cual es descrita como una foliación con orientación N42/44SE, que contiene estructuras tipo S-C, y está presente en todos los litotipos. Las características petrográficas de las zonas sulfuradas auríferas del depósito pilar son semejantes entre sí. A continuación, se hace una descripción de las características de los minerales opacos:

La arsenopirita es el mineral más abundante y se presenta en todos los litotipos, ocurre como cristales euédricos a subédricos, con tamaño entre $0,1 \mathrm{~mm}$ a 0,4 $\mathrm{mm}$, que se clasifican en dos grupos; i) Arsenopirita I, relacionada a aquellas en paragénesis con otros sulfuros principalmente pirrotita y en menor proporción con la pirita (Figura 4A); ii) Arsenopirita II, representada por 
cristales individuales y euédricos (Figura 4B). Algunos cristales presentan inclusiones de cuarzo, calcopirita y oro. También ocurre como inclusiones en la pirrotita y es común encontrar bandas de clorita en los bordes de los cristales euédricos.

La pirrotita de manera general se encuentra como cristales individuales con límites rectilíneos y tamaño de cristal entre $0,2 \mathrm{~mm}$ a $0,6 \mathrm{~mm}$, diseminados o estirados según el plano de foliación $\mathrm{S}_{3}$ (Figura 4C) y ocasionalmente de apariencia masiva (Figura 4D). Se encuentra asociada con calcopirita y más comúnmente con pirita. Localmente presentan inclusiones de pentlandita. Para los esquistos carbonosos, esta fase mineral ocurre de forma tabular, paralela a la foliación $\mathrm{S}_{3}$, con textura poiquiloblástica con inclusiones de cuarzo, carbonato, clorita y/o magnetita. En las venas de cuarzo \pm carbonato presenta superficies con texturas porosas y faces corroídas.
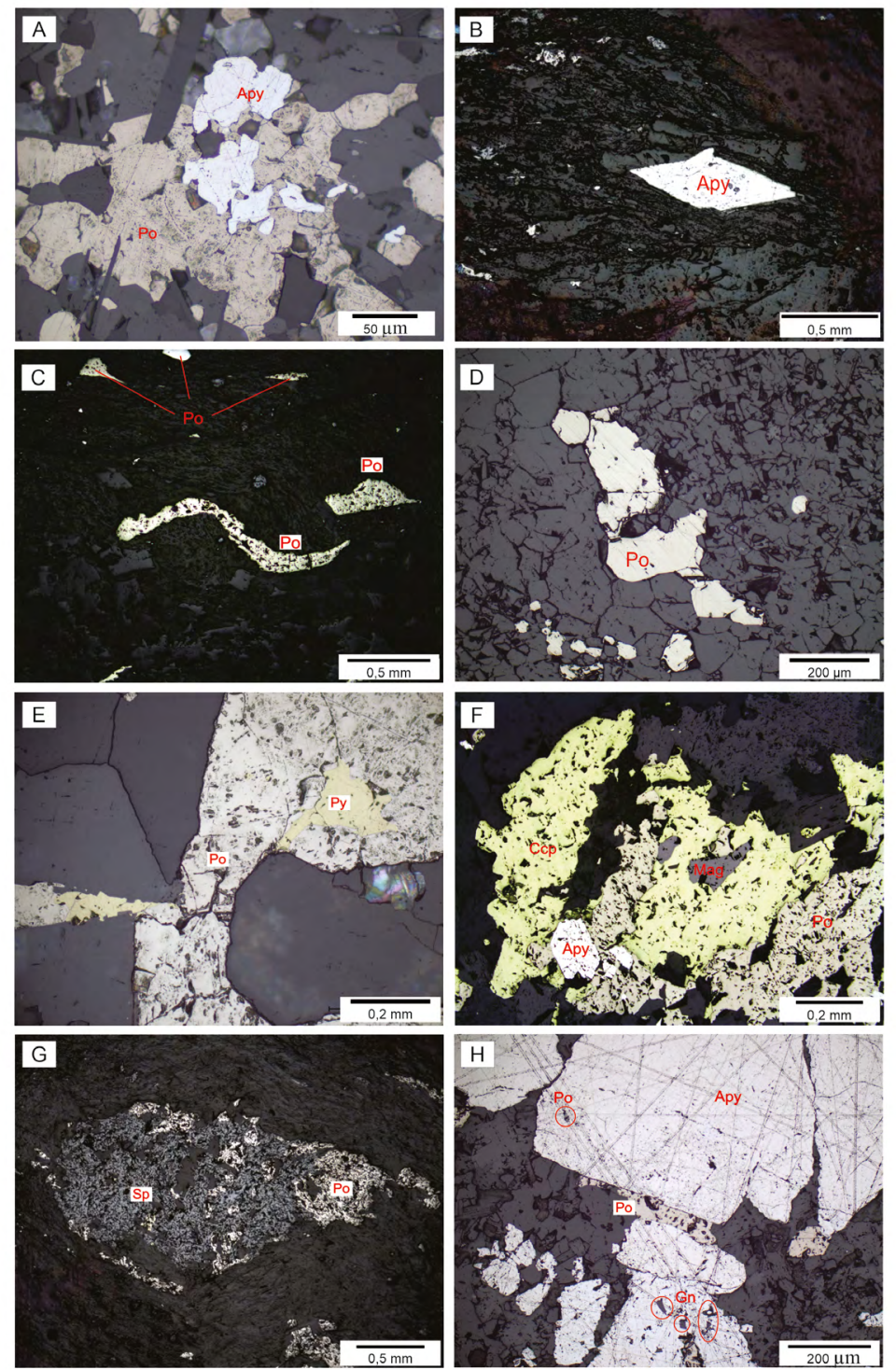

Figura 4. Fotomicrografías de los principales sulfuros en luz reflejada asociadas al depósito Pilar: A. Cristal de arsenopirita I (Apy) en contacto con pirrotita (Po) (muestra PL5B). B. Cristal individual euédrico de arsenopirita II (Apy) (muestra PL10A). C. Pirrotita tabular (muestra PL8D). D. Cristal de pirrotita individual (muestra P15B). E. Cristales de pirita (Py) asociada con pirrotita (muestra PL4D). F. Paragénesis de pirrotita + arsenopirita (Apy) + calcopirita + magnetita (Mag) (muestra PL16D). G. Esfalerita (Sp) en contacto con pirrotita (Po) como producto de alteración hidrotermal (muestra PL16D). H. Galena (Gn) como inclusiones en cristal de arsenopirita (PL15A). 

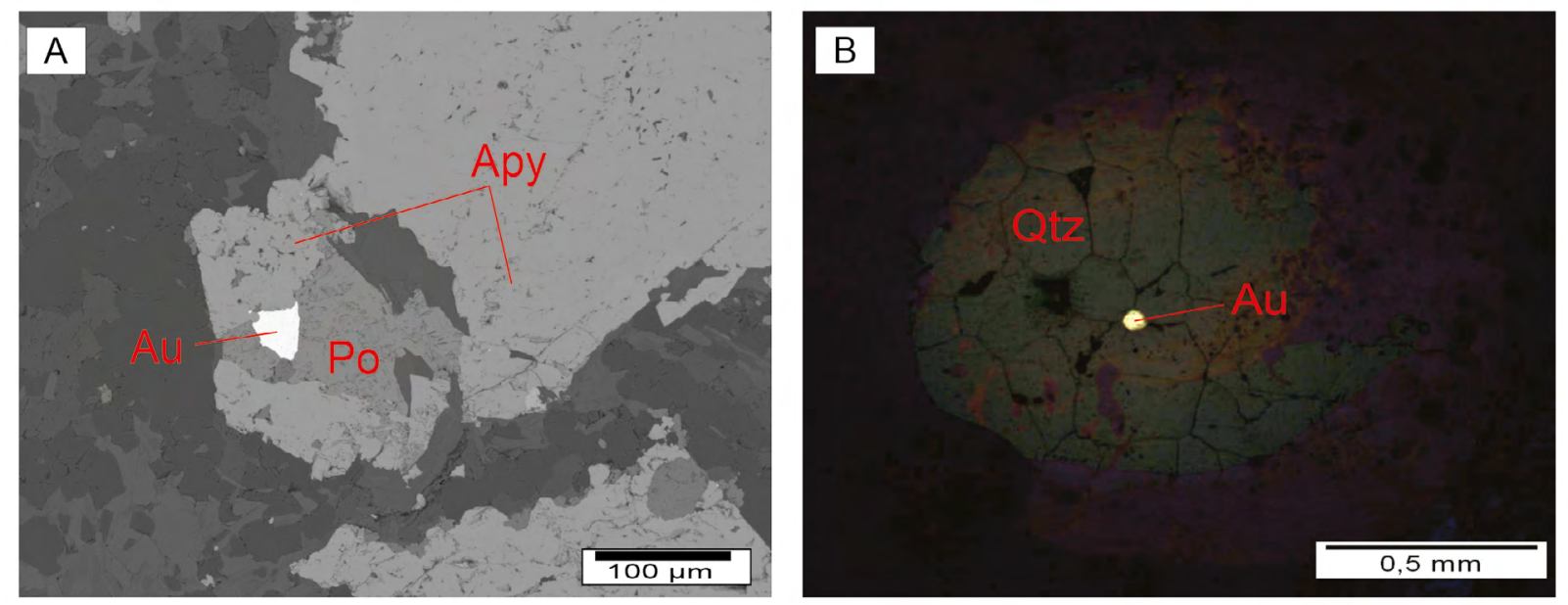

Figura 5. Fotomicrografía de láminas delgadas pulidas del BIF y venas de cuarzo: A. Oro (Au) asociado a la arsenopirita (Apy) y pirrotita (Po) (microsonda electrónica) (muestra PL4A). B. Oro libre en venas de cuarzo (luz reflejada) (muestra PL14D).

La pirita se presenta como cristales subédricos a anédricos, de tamaño de cristal entre $0,1 \mathrm{~mm}$ a $0,3 \mathrm{~mm}$, con límites irregulares y apariencia lisa, diseminada en la roca y asociada a la pirrotita y a la arsenopirita (Figura 4E) o en la forma de inclusiones en estas fases minerales y su presencia disminuye cerca de las zonas mineralizadas.

La calcopirita ocurre como cristales anédricos de tamaño entre $0,1 \mathrm{~mm}$ a $0,3 \mathrm{~mm}$, asociados principalmente a la pirrotita (Figura 4F) y como inclusiones en la arsenopirita.

La esfalerita y la galena se presentan como inclusiones principalmente en pirrotita, con tamaño de cristal hasta $40 \mu \mathrm{m}$, y se encuentran en las venas relacionadas a procesos hidrotermales (Figura 4G; Figura 4H, respectivamente).

El oro no se observa en muestras de mano y su identificación fue realizada mediante EDX (Energydispersive X-ray spectroscopy), seguida por la descripción de lámina delgada-pulida. Se presenta diseminado en el BIF, asociado principalmente a la arsenopirita (Figura 5A) y de forma libre en las venas de cuarzo, con tamaño de grano de $50 \mu \mathrm{m}$ hasta 0,3 $\mathrm{mm}$ (Figura 5B).

\section{Análisis de química mineral}

De acuerdo con el orden de abundancia en los análisis petrográficos, la fórmula estructural de las fases opacas asociadas al depósito Pilar son: arsenopirita I $\left(\mathrm{Fe}_{(0,90-0,95)}\right.$ $\left.\mathrm{As}_{(0,88-0,94)} \mathrm{S}_{(0,94-1,02)}\right)$, arsenopirita II $\left(\mathrm{Fe}_{(0,89-0,90)} \mathrm{As}_{(0,86-0,93)}\right.$ $\mathrm{S}_{(0,90-0,94)}$ ), pirrotita $\left(\mathrm{Fe}_{(1,059)} \mathrm{S}_{(1,214)}\right)$, pirita $\left(\mathrm{Fe}_{(1,24)} \mathrm{S}_{(2,50)}\right)$, calcopirita $\left(\begin{array}{lll}\mathrm{Cu}_{(1,09)} & \mathrm{Fe}_{(1,09)} & \mathrm{S} \\ (2,15)\end{array}\right)$, esfalerita $\left(\mathrm{Zn}_{(0,69)}\right.$ $\left.\mathrm{Fe}_{(0,107)} \mathrm{S}_{(0,991)}\right)$ y galena $\left(\mathrm{Pb}_{(0,83)} \mathrm{S}_{(0,80)}\right)$. Estos sulfuros son representados en el diagrama de composición de Clark (1960) el cual relaciona los componentes elementales de S, Fe y As (Figura 6).

La composición química general de las arsenopiritas con fórmula FeAsS son; i) arsenopirita I, Fe desde 34,37 hasta 35,05 wt. $\%$, As 44,75 hasta 46,48 wt. $\%$, y S 20,23 hasta 21,99 wt. \%; ii) arsenopirita II, Fe desde 33,46 hasta 34,19 wt. $\%$, As 45,23 hasta 46,85 wt. $\%$, y S 19,23 hasta 20,96 wt. \% (Tabla 2).

La pirrotita $\left(\mathrm{Fe}_{1-\mathrm{x}} \mathrm{S}\right)$ posee $\mathrm{X}$ variando entre 0 y 0,08 y contenido en $\mathrm{Fe} \approx 59,14$ wt. $\%$ y $\mathrm{S} \approx 38,93$ wt. $\%$, con pequeñas cantidades de Ni entre 0,02 hasta 0,65 wt. $\%$, Co entre 0,03 hasta 0,11 wt. \% (Tabla 2). Los valores de la media para Au y Ag son menores que 0,01 wt. \%.

La calcopirita $\left(\mathrm{CuFeS}_{2}\right)$, con $\mathrm{Cu} \approx 33,47$ wt. $\%$, $\mathrm{Fe} \approx 29,42$ wt. $\%, S \approx 33,44$ wt. $\%$, presentando elementos trazas de $\mathrm{Pb}$ y $\mathrm{Zn}$ (Tabla 3).

La pirita $\left(\mathrm{FeS}_{2}\right)$ presenta porcentajes en peso de $\mathrm{Fe} \approx 45,55$ y $\mathrm{S} \approx 52,64$ para cuatro cristales con elementos trazas de $\mathrm{Pb}$ y $\mathrm{Cd}$ (Tabla 4). 


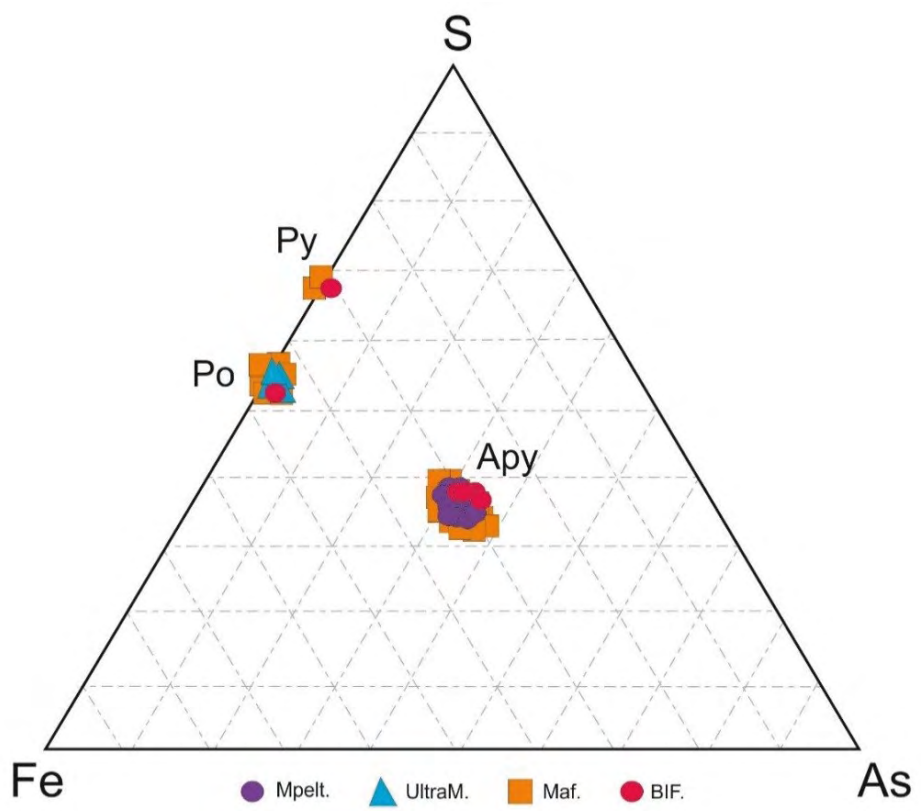

Figura 6. Diagrama de clasificación de sulfuros (Clark, 1960). Arsenopirita (Apy), pirrotita (Po), pirita (Py), metapelítica (Mpelt), meta-ultramáfica (UltraM), metamáfica (Maf) y Formación Ferrífera Bandeada (BIF). Los valores graficados corresponden a wt. \%.

Tabla 2. Resultados de química mineral para arsenopirita (wt. \%), recalculados en átomos por fórmula unitaria (afu) y porcentaje atómico (at. \%).

\begin{tabular}{|c|c|c|c|c|c|c|c|c|c|c|c|c|c|c|}
\hline \multirow{2}{*}{$\frac{\text { No. Muestra }}{\text { No. Punto }}$} & \multicolumn{3}{|c|}{ PL4A } & \multicolumn{3}{|c|}{ PL6A } & \multicolumn{6}{|c|}{ PL6A1 } & \multirow{2}{*}{$\frac{\text { PL10A }}{7 \_11}$} & \multirow{2}{*}{$\frac{\text { PL17C }}{6 \_20}$} \\
\hline & 9_57 & 3_19 & 9_58 & $1 \_3$ & 7_11 & 244 & 266 & 3_8 & 7_27 & 7_29 & 7_30 & 3_11 & & \\
\hline \multicolumn{15}{|l|}{ wt. \% } \\
\hline $\mathrm{S}$ & 20,23 & 20,39 & 21,13 & 20,23 & 21,00 & 20,60 & 21,99 & 20,40 & 19,38 & 20,65 & 20,96 & 20,52 & 19,23 & 18,44 \\
\hline $\mathrm{Fe}$ & 33,46 & 34,37 & 33,79 & 34,86 & 35,52 & 35,24 & 34,97 & 34,19 & 33,62 & 33,92 & 34,75 & 35,02 & 31,25 & 31,20 \\
\hline As & 46,80 & 45,23 & 46,15 & 45,60 & 44,75 & 44,56 & 43,36 & 45,66 & 46,85 & 46,22 & 44,62 & 42,95 & 46,75 & 46,48 \\
\hline $\mathrm{Au}$ & 0,01 & 0,06 & 0,01 & 0,04 & 0,00 & 0,00 & 0,01 & 0,01 & 0,00 & 0,00 & 0,03 & 0,06 & 0,00 & 0,03 \\
\hline $\mathrm{Ag}$ & 0,00 & 0,01 & 0,01 & 0,001 & 0,00 & 0,00 & 0,00 & 0,001 & 0,01 & 0,00 & 0,007 & 0,00 & 0,006 & 0,00 \\
\hline $\mathrm{Cu}$ & 0,04 & 0,00 & 0,00 & 0,00 & 0,00 & 0,00 & 0,00 & 0,00 & 0,02 & 0,00 & 0,03 & 0,07 & 0,00 & 0,01 \\
\hline Co & 0,17 & 0,04 & 0,13 & 0,07 & 0,09 & 0,07 & 0,04 & 0,10 & 0,12 & 0,10 & 0,04 & 0,12 & 2,18 & 0,01 \\
\hline $\mathrm{Cd}$ & 0,00 & 0,01 & 0,00 & 0,00 & 0,02 & 0,00 & 0,00 & 0,00 & 0,00 & 0,00 & 0,01 & 0,00 & 0,04 & 0,00 \\
\hline $\mathrm{Zn}$ & 0,00 & 0,00 & 0,00 & 0,00 & 0,00 & 0,04 & 0,00 & 0,00 & 0,01 & 0,003 & 0,00 & 0,00 & 0,004 & 0,00 \\
\hline Mo & 0,04 & 0,05 & 0,03 & 0,05 & 0,03 & 0,00 & 0,05 & 0,03 & 0,03 & 0,07 & 0,06 & 0,00 & 0,02 & 0,07 \\
\hline $\mathrm{Pb}$ & 0,08 & 0,10 & 0,00 & 0,01 & 0,09 & 0,07 & 0,09 & 0,13 & 0,11 & 0,04 & 0,07 & 0,13 & 0,00 & 0,09 \\
\hline $\mathrm{Bi}$ & 0,00 & 0,00 & 0,00 & 0,00 & 0,04 & 0,00 & 0,05 & 0,00 & 0,07 & 0,00 & 0,06 & 0,01 & 0,00 & 0,02 \\
\hline $\mathrm{Ga}$ & 0,00 & 0,00 & 0,00 & 0,00 & 0,00 & 0,00 & 0,00 & 0,00 & 0,00 & 0,00 & 0,00 & 0,04 & 0,00 & 0,01 \\
\hline Total & 100,90 & 100,31 & 101,29 & 100,94 & 101,59 & 100,64 & 100,64 & 100,55 & 100,29 & 101,11 & 100,68 & 98,95 & 100,51 & 96,85 \\
\hline \multicolumn{15}{|c|}{ Átomos por fórmula unitaria } \\
\hline $\mathrm{S}$ & 0,94 & 0,95 & 0,98 & 0,94 & 0,97 & 0,96 & 1,02 & 0,95 & 0,90 & 0,96 & 0,97 & 0,97 & 0,90 & 0,89 \\
\hline $\mathrm{Fe}$ & 0,89 & 0,92 & 0,90 & 0,93 & 0,94 & 0,94 & 0,93 & 0,91 & 0,90 & 0,90 & 0,93 & 0,95 & 0,84 & 0,87 \\
\hline As & 0,93 & 0,90 & 0,91 & 0,90 & 0,88 & 0,89 & 0,86 & 0,91 & 0,94 & 0,92 & 0,89 & 0,87 & 0,93 & 0,96 \\
\hline \multicolumn{15}{|c|}{ Porcentaje atómico } \\
\hline$\% \mathrm{~S}$ & 34,51 & 34,72 & 35,41 & 34,39 & 35,14 & 34,69 & 36,55 & 34,47 & 34,25 & 34,74 & 35,13 & 34,84 & 33,63 & 32,79 \\
\hline$\%$ As & 32,01 & 31,99 & 31,61 & 31,83 & 31,66 & 32,41 & 31,02 & 33,01 & 32,79 & 32,32 & 32,03 & 31,83 & 34,98 & 35,36 \\
\hline
\end{tabular}


Tabla 3. Resultados de química mineral para pirrotita (wt. \%), recalculados en átomos por fórmula unitaria (afu) y porcentaje atómico (at. \%).

\begin{tabular}{|c|c|c|c|c|c|c|c|c|c|c|c|c|c|c|}
\hline \multirow{2}{*}{$\begin{array}{c}\begin{array}{c}\text { No. } \\
\text { Muestra }\end{array} \\
\text { No. Punto } \\
\end{array}$} & \multirow{2}{*}{$\begin{array}{c}\text { PL1A } \\
8 \_21\end{array}$} & \multicolumn{12}{|c|}{ PL4A } & \multirow{2}{*}{$\begin{array}{c}\text { PL5C } \\
1 \_1\end{array}$} \\
\hline & & $2 \_13$ & 3_15 & 3_18 & $6 \_40$ & $6 \_41$ & $6 \_42$ & 8_46 & $9 \_59$ & 11_71 & $12 \_87$ & 13_100 & 13_102 & \\
\hline \multicolumn{15}{|l|}{ wt. $\%$} \\
\hline $\mathrm{S}$ & 39,75 & 39,67 & 39,98 & 39,89 & 39,83 & 39,81 & 39,17 & 39,60 & 39,58 & 39,31 & 40,13 & 40,38 & 39,32 & 39,81 \\
\hline $\mathrm{Fe}$ & 59,21 & 59,68 & 59,85 & 59,83 & 59,16 & 59,60 & 59,63 & 59,91 & 59,94 & 59,18 & 59,80 & 59,23 & 59,64 & 60,07 \\
\hline $\mathrm{Au}$ & 0,00 & 0,00 & 0,00 & 0,00 & 0,005 & 0,00 & 0,00 & 0,00 & 0,00 & 0,00 & 0,00 & 0,00 & 0,00 & 0,03 \\
\hline $\mathrm{Ag}$ & 0,00 & 0,02 & 0,00 & 0,003 & 0,001 & 0,002 & 0,00 & 0,005 & 0,00 & 0,00 & 0,001 & 0,00 & 0,00 & 0,00 \\
\hline $\mathrm{Cu}$ & 0,02 & 0,00 & 0,03 & 0,04 & 0,02 & 0,006 & 0,00 & 0,00 & 0,001 & 0,00 & 0,00 & 0,00 & 0,00 & 0,01 \\
\hline $\mathrm{Co}$ & 0,07 & 0,04 & 0,04 & 0,07 & 0,03 & 0,03 & 0,04 & 0,06 & 0,09 & 0,05 & 0,07 & 0,05 & 0,05 & 0,06 \\
\hline $\mathrm{Cd}$ & 0,03 & 0,01 & 0,02 & 0,00 & 0,009 & 0,008 & 0,00 & 0,00 & 0,03 & 0,001 & 0,02 & 0,03 & 0,04 & 0,00 \\
\hline $\mathrm{Zn}$ & 0,00 & 0,10 & 0,00 & 0,00 & 0,04 & 0,00 & 0,00 & 0,00 & 0,00 & 0,07 & 0,00 & 0,01 & 0,04 & 0,00 \\
\hline $\mathrm{Ni}$ & 0,54 & 0,07 & 0,04 & 0,07 & 0,07 & 0,07 & 0,05 & 0,08 & 0,16 & 0,001 & 0,02 & 0,06 & 0,15 & 0,13 \\
\hline Mo & 0,00 & 0,11 & 0,08 & 0,03 & 0,13 & 0,12 & 0,08 & 0,06 & 0,04 & 0,10 & 0,05 & 0,05 & 0,09 & 0,09 \\
\hline $\mathrm{Pb}$ & 0,18 & 0,22 & 0,17 & 0,16 & 0,04 & 0,01 & 0,12 & 0,07 & 0,10 & 0,11 & 0,09 & 0,12 & 0,18 & 0,14 \\
\hline $\mathrm{Bi}$ & 0,00 & 0,008 & 0,00 & 0,02 & 0,00 & 0,00 & 0,02 & 0,05 & 0,00 & 0,00 & 0,00 & 0,00 & 0,00 & 0,00 \\
\hline $\mathrm{Ga}$ & 0,00 & 0,00 & 0,00 & 0,00 & 0,00 & 0,00 & 0,00 & 0,00 & 0,00 & 0,00 & 0,00 & 0,00 & 0,00 & 0,00 \\
\hline $\mathrm{Se}$ & 0,00 & 0,02 & 0,03 & 0,04 & 0,02 & 0,00 & 0,03 & 0,00 & 0,03 & 0,02 & 0,07 & 0,04 & 0,00 & 0,00 \\
\hline Total & 99,85 & 99,98 & 100,24 & 100,15 & 99,35 & 99,67 & 99,16 & 99,83 & 99,98 & 98,84 & 100,26 & 99,98 & 99,50 & 100,34 \\
\hline \multicolumn{15}{|c|}{ Átomos por fórmula unitaria } \\
\hline $\mathrm{S}$ & 1,24 & 1,23 & 1,24 & 1,24 & 1,24 & 1,24 & 1,22 & 1,23 & 1,23 & 1,22 & 1,25 & 1,26 & 1,23 & 1,24 \\
\hline $\mathrm{Fe}$ & 1,06 & 1,06 & 1,07 & 1,07 & 1,06 & 1,07 & 1,07 & 1,07 & 1,07 & 1,06 & 1,07 & 1,06 & 1,07 & 1,08 \\
\hline $\mathrm{Ni}$ & 0,00 & 0,00 & 0,001 & 0,001 & 0,001 & 0,001 & 0,001 & 0,001 & 0,003 & 0,00 & 0,00 & 0,001 & 0,002 & 0,002 \\
\hline \multicolumn{15}{|c|}{ Porcentaje atómico } \\
\hline$\% \mathrm{Fe}$ & 45,91 & 46,31 & 46,20 & 46,24 & 45,99 & 46,19 & 46,62 & 46,45 & 46,45 & 46,35 & 46,09 & 45,69 & 46,49 & 46,37 \\
\hline$\% \mathrm{Ni}$ & 0,40 & 0,05 & 0,02 & 0,05 & 0,05 & 0,04 & 0,04 & 0,06 & 0,12 & 0,001 & 0,02 & 0,04 & 0,11 & 0,09 \\
\hline
\end{tabular}

Tabla 4. Resultados de química mineral para calcopirita (wt. \%), recalculados en átomos por fórmula unitaria (afu) y porcentaje atómico (at. \%).

\begin{tabular}{|c|c|c|c|c|c|c|c|c|c|c|c|c|c|c|c|c|c|c|c|}
\hline \multirow{2}{*}{$\begin{array}{c}\begin{array}{c}\text { No. } \\
\text { Muestra }\end{array} \\
\text { No. Punto }\end{array}$} & \multicolumn{4}{|c|}{ PL10A } & \multirow{2}{*}{$\frac{\text { PL15B }}{11 \_1}$} & \multirow{2}{*}{$\begin{array}{l}\text { PL4A } \\
11 \_70\end{array}$} & \multirow{2}{*}{$\frac{\text { PL16D }}{2 \_4}$} & \multirow{2}{*}{$\begin{array}{c}\text { PL15B } \\
5 \_11\end{array}$} & \multicolumn{3}{|c|}{ PL17D } & \multirow{2}{*}{$\begin{array}{c}\text { PL6A } \\
2 \_5\end{array}$} & \multicolumn{2}{|c|}{ PL14D } & \multicolumn{5}{|c|}{ PL17C } \\
\hline & 4_17 & 5_14 & 7_10 & 3_21 & & & & & 5_26 & 4_17 & $5 \_23$ & & $2 \_6$ & 8_17 & 8_32 & 8_29 & 3_11 & 13_44 & 8_33 \\
\hline \multicolumn{20}{|l|}{ wt. \% } \\
\hline As & 0,00 & 0,00 & 0,00 & 0,00 & 0,00 & 0,00 & 0,00 & 0,00 & 0,00 & 0,00 & 0,00 & 0,00 & 0,00 & 0,00 & 0,00 & 0,00 & 0,00 & 0,00 & 0,00 \\
\hline $\mathrm{Zn}$ & 0,04 & 0,05 & 0,00 & 0,06 & 0,02 & 0,12 & 0,00 & 0,06 & 0,07 & 0,02 & 0,03 & 0,13 & 0,01 & 0,04 & 0,04 & 0,05 & 0,00 & 0,006 & 0,00 \\
\hline $\mathrm{Ga}$ & 0,00 & 0,00 & 0,00 & 0,00 & 0,00 & 0,00 & 0,00 & 0,00 & 0,00 & 0,00 & 0,00 & 0,00 & 0,00 & 0,00 & 0,00 & 0,00 & 0,00 & 0,00 & 0,00 \\
\hline $\mathrm{Se}$ & 0,00 & 0,04 & 0,01 & 0,01 & 0,06 & 0,01 & 0,00 & 0,04 & 0,004 & 0,03 & 0,03 & 0,02 & 0,06 & 0,00 & 0,00 & 0,05 & 0,04 & 0,06 & 0,00 \\
\hline S & 34,83 & 34,27 & 34,15 & 33,86 & 33,85 & 33,79 & 33,77 & 33,68 & 33,64 & 33,53 & 33,43 & 33,32 & 33,38 & 33,17 & 32,64 & 32,59 & 32,53 & 32,39 & 32,32 \\
\hline $\mathrm{Pb}$ & 0,07 & 0,09 & 0,02 & 0,16 & 0,13 & 0,16 & 0,16 & 0,05 & 0,12 & 0,05 & 0,16 & 0,08 & 0,14 & 0,12 & 0,09 & 0,00 & 0,17 & 0,30 & 0,12 \\
\hline $\mathrm{Bi}$ & 0,00 & 0,03 & 0,00 & 0,13 & 0,00 & 0,05 & 0,04 & 0,12 & 0,03 & 0,00 & 0,00 & 0,00 & 0,00 & 0,01 & 0,00 & 0,00 & 0,00 & 0,00 & 0,03 \\
\hline $\mathrm{Cd}$ & 0,00 & 0,01 & 0,01 & 0,00 & 0,05 & 0,00 & 0,00 & 0,00 & 0,003 & 0,00 & 0,00 & 0,04 & 0,00 & 0,04 & 0,00 & 0,00 & 0,00 & 0,00 & 0,01 \\
\hline $\mathrm{Fe}$ & 30,36 & 30,37 & 29,60 & 29,84 & 29,78 & 30,74 & 30,16 & 30,16 & 29,92 & 30,46 & 29,59 & 30,11 & 30,86 & 29,87 & 27,75 & 27,72 & 29,13 & 27,97 & 28,01 \\
\hline Co & 0,024 & 0,037 & 0,04 & 0,06 & 0,02 & 0,02 & 0,05 & 0,06 & 0,05 & 0,02 & 0,03 & 0,02 & 0,02 & 0,05 & 0,035 & 0,00 & 0,01 & 0,05 & 0,006 \\
\hline $\mathrm{Cu}$ & 34,57 & 34,86 & 34,47 & 34,36 & 33,40 & 34,61 & 34,66 & 34,62 & 34,19 & 33,77 & 34,07 & 34,48 & 34,01 & 34,42 & 31,46 & 30,92 & 33,01 & 30,95 & 31,31 \\
\hline $\mathrm{Ni}$ & 0,00 & 0,02 & 0,00 & 0,00 & 0,00 & 0,00 & 0,004 & 0,04 & 0,00 & 0,003 & 0,00 & 0,00 & 0,00 & 0,004 & 0,00 & 0,004 & 0,00 & 0,02 & 0,005 \\
\hline Mo & 0,06 & 0,08 & 0,01 & 0,06 & 0,04 & 0,05 & 0,05 & 0,06 & 0,08 & 0,04 & 0,07 & 0,11 & 0,00 & 0,10 & 0,06 & 0,08 & 0,11 & 0,04 & 0,05 \\
\hline $\mathrm{Au}$ & 0,00 & 0,00 & 0,00 & 0,00 & 0,02 & 0,00 & 0,00 & 0,00 & 0,00 & 0,00 & 0,00 & 0,07 & 0,03 & 0,00 & 0,03 & 0,00 & 0,00 & 0,00 & 0,00 \\
\hline $\mathrm{Ag}$ & 0,00 & 0,03 & 0,04 & 0,03 & 0,02 & 0,01 & 0,03 & 0,02 & 0,01 & 0,02 & 0,04 & 0,00 & 0,02 & 0,01 & 0,02 & 0,02 & 0,02 & 0,003 & 0,001 \\
\hline Total & 99,95 & 99,87 & 98,34 & 98,58 & 97,38 & 99,56 & 98,92 & 98,92 & 98,13 & 97,95 & 97,45 & 98,44 & 98,53 & 97,84 & 92,12 & 91,43 & 95,01 & 91,78 & 91,85 \\
\hline
\end{tabular}




\section{Continuación Tabla 4.}

\begin{tabular}{|c|c|c|c|c|c|c|c|c|c|c|c|c|c|c|c|c|c|c|c|}
\hline \multirow{2}{*}{$\begin{array}{c}\begin{array}{c}\text { No. } \\
\text { Muestra }\end{array} \\
\text { No. Punto }\end{array}$} & \multicolumn{4}{|c|}{ PL10A } & \multirow{2}{*}{$\begin{array}{c}\text { PL15B } \\
1 \_1 \\
\end{array}$} & \multirow{2}{*}{$\begin{array}{l}\text { PL4A } \\
11 \_70 \\
\end{array}$} & \multirow{2}{*}{$\begin{array}{c}\text { PL16D } \\
2 \_4 \\
\end{array}$} & \multirow{2}{*}{$\begin{array}{c}\text { PL15B } \\
5 \_11\end{array}$} & \multicolumn{3}{|c|}{ PL17D } & \multirow{2}{*}{$\begin{array}{c}\text { PL6A } \\
2 \_5 \\
\end{array}$} & \multicolumn{2}{|c|}{ PL14D } & \multicolumn{5}{|c|}{ PL17C } \\
\hline & 4_17 & $5 \_14$ & $7 \_10$ & 3_21 & & & & & $5 \_26$ & 4_17 & $5 \_23$ & & 2 & 8_17 & $8 \_32$ & 8_29 & 3_11 & 13_44 & 8_33 \\
\hline \multicolumn{20}{|l|}{ wt. \% } \\
\hline \multicolumn{20}{|c|}{ Átomos por fórmula unitaria } \\
\hline $\mathrm{S}$ & 2,17 & 2,14 & 2,17 & 2,14 & 2,17 & 2,12 & 2,13 & 2,12 & 2,14 & 2,14 & 2,14 & 2,11 & 2,11 & 2,11 & 2,21 & 2,22 & 2,14 & 2,20 & 2,20 \\
\hline $\mathrm{Fe}$ & 1,09 & 1,09 & 1,08 & 1,08 & 1,10 & 1,11 & 1,09 & 1,09 & 1,09 & 1,11 & 1,09 & 1,10 & 1,12 & 1,09 & 1,08 & 1,09 & 1,10 & 1,09 & 1,09 \\
\hline $\mathrm{Cu}$ & 1,09 & 1,10 & 1,10 & 1,10 & 1,08 & 1,09 & 1,10 & 1,10 & 1,10 & 1,09 & 1,10 & 1,10 & 1,09 & 1,11 & 1,07 & 1,06 & 1,09 & 1,06 & 1,07 \\
\hline \multicolumn{20}{|c|}{ Porcentaje atómico } \\
\hline$\% \mathrm{~S}$ & 49,97 & 49,46 & 49,83 & 49,56 & 49,93 & 49,05 & 49,25 & 49,19 & 49,42 & 49,27 & 49,45 & 49,05 & 48,90 & 49,01 & 50,65 & 50,84 & 49,36 & 50,56 & 50,35 \\
\hline$\% \mathrm{Fe}$ & 25,01 & 25,16 & 24,79 & 25,07 & 25,22 & 25,61 & 25,25 & 25,29 & 25,24 & 25,69 & 25,12 & 25,39 & 25,96 & 25,33 & 24,72 & 24,83 & 25,37 & 25,07 & 25,04 \\
\hline$\% \mathrm{Cu}$ & 25,02 & 25,38 & 25,38 & 25,37 & 24,86 & 25,34 & 25,50 & 25,51 & 25,34 & 25,04 & 25,42 & 25,56 & 25,14 & 25,65 & 24,63 & 24,33 & 25,27 & 24,38 & 24,61 \\
\hline
\end{tabular}

La galena $(\mathrm{PbS})$ presenta una composición de $\mathrm{Pb} \approx 84,11$ wt. $\%, S \approx 12,58$ wt. $\%$ y Ag de 0,70 wt. $\%$ (Tabla 5 ). La esfalerita ( $\mathrm{ZnS})$, con $\mathrm{Zn}$ desde 57,88 hasta 62,57 wt. $\%$, S desde 30,92 hasta 32,66 wt. $\%$ y $\mathrm{Fe} \approx 5,96$ wt. $\%$ (Tabla 6). La galena y esfalerita ocurren en venas hidrotermales y depósitos de sustitución asociados con pirrotita, pirita y magnetita.

Tabla 5. Resultados de química mineral para pirita (wt. \%), recalculados en átomos por fórmula unitaria (afu) y porcentaje atómico (at. \%).

\begin{tabular}{|c|c|c|c|c|}
\hline \multirow{2}{*}{$\begin{array}{c}\text { No. Muestra } \\
\text { No. Punto }\end{array}$} & \multicolumn{3}{|c|}{ PL16D } & \multirow{2}{*}{$\frac{\text { PL17D }}{12 \_56}$} \\
\hline & 1_1 & 8_18 & 7_15 & \\
\hline \multicolumn{5}{|l|}{ wt. $\%$} \\
\hline As & 0,00 & 0,00 & 0,00 & 0,04 \\
\hline $\mathrm{Zn}$ & 0,00 & 0,00 & 0,03 & 0,00 \\
\hline $\mathrm{Ga}$ & 0,00 & 0,00 & 0,00 & 0,00 \\
\hline $\mathrm{Se}$ & 0,003 & 0,01 & 0,05 & 0,01 \\
\hline S & 53,23 & 53,20 & 53,16 & 50,96 \\
\hline $\mathrm{Pb}$ & 0,12 & 0,23 & 0,12 & 0,26 \\
\hline $\mathrm{Bi}$ & 0,00 & 0,00 & 0,00 & 0,00 \\
\hline $\mathrm{Cd}$ & 0,02 & 0,01 & 0,00 & 0,01 \\
\hline $\mathrm{Fe}$ & 45,29 & 45,12 & 45,12 & 46,65 \\
\hline $\mathrm{Co}$ & 0,02 & 0,09 & 0,06 & 0,05 \\
\hline $\mathrm{Cu}$ & 0,03 & 0,00 & 0,02 & 0,00 \\
\hline $\mathrm{Ni}$ & 0,05 & 0,00 & 0,02 & 0,06 \\
\hline Mo & 0,08 & 0,12 & 0,13 & 0,09 \\
\hline $\mathrm{Au}$ & 0,00 & 0,00 & 0,00 & 0,00 \\
\hline $\mathrm{Ag}$ & 0,00 & 0,00 & 0,01 & 0,01 \\
\hline Total & 98,84 & 98,78 & 98,74 & 98,14 \\
\hline \multicolumn{5}{|c|}{ Átomos por fórmula unitaria } \\
\hline $\mathrm{S}$ & 1,66 & 1,66 & 1,66 & 1,59 \\
\hline $\mathrm{Fe}$ & 0,81 & 0,81 & 0,80 & 0,84 \\
\hline \multicolumn{5}{|c|}{ Porcentaje atómico } \\
\hline$\% \mathrm{~S}$ & 67,18 & 67,25 & 67,24 & 65,55 \\
\hline$\% \mathrm{Fe}$ & 32,82 & 32,75 & 32,76 & 34,45 \\
\hline $\mathrm{Co} / \mathrm{Ni}$ & 0,4 & 0 & 3 & 0,83 \\
\hline
\end{tabular}

Tabla 6. Resultados de química mineral para galena (wt. \%), recalculados en átomos por fórmula unitaria $(a f u)$ y porcentaje atómico (at. \%).

\begin{tabular}{|c|c|c|c|c|}
\hline No. Muestra & & L10A & & PL17D \\
\hline No. Punto & $10 \_2$ & $10 \_5$ & $10 \_4$ & 4_18 \\
\hline \multicolumn{5}{|l|}{ wt. $\%$} \\
\hline As & 0,00 & 0,00 & 0,00 & 0,00 \\
\hline $\mathrm{Zn}$ & 0,01 & 0,01 & 0,00 & 0,00 \\
\hline $\mathrm{Ga}$ & 0,00 & 0,00 & 0,00 & 0,00 \\
\hline $\mathrm{Se}$ & 0,59 & 0,55 & 0,61 & 0,07 \\
\hline S & 12,87 & 12,58 & 12,57 & 12,28 \\
\hline $\mathrm{Pb}$ & 84,56 & 84,38 & 84,47 & 83,04 \\
\hline $\mathrm{Bi}$ & 0,27 & 0,11 & 0,39 & 0,60 \\
\hline $\mathrm{Cd}$ & 0,08 & 0,13 & 0,06 & 0,04 \\
\hline $\mathrm{Fe}$ & 0,07 & 0,05 & 0,00 & 0,16 \\
\hline Co & 0,00 & 0,00 & 0,02 & 0,00 \\
\hline $\mathrm{Cu}$ & 0,00 & 0,00 & 0,00 & 0,01 \\
\hline $\mathrm{Ni}$ & 0,02 & 0,01 & 0,04 & 0,00 \\
\hline Mo & 0,04 & 0,00 & 0,00 & 0,00 \\
\hline $\mathrm{Au}$ & 0,02 & 0,00 & 0,00 & 0,00 \\
\hline $\mathrm{Ag}$ & 0,11 & 0,11 & 0,16 & 0,31 \\
\hline Total & 98,66 & 97,94 & 98,33 & 96,52 \\
\hline \multicolumn{5}{|c|}{ Átomos por fórmula unitaria } \\
\hline $\mathrm{S}$ & 0,81 & 0,80 & 0,80 & 0,79 \\
\hline $\mathrm{Pb}$ & 0,83 & 0,83 & 0,83 & 0,83 \\
\hline \multicolumn{5}{|c|}{ Porcentaje atómico } \\
\hline$\% \mathrm{~S}$ & 49,59 & 49,08 & 49,03 & 48,88 \\
\hline$\% \mathrm{~Pb}$ & 50,41 & 50,92 & 50,97 & 51,12 \\
\hline
\end{tabular}


El oro fue analizado en tres láminas, corresponde a oro libre y a venas de cuarzo con iguales valores relacionado a $\mathrm{Au}=83,96 \%$ y $\mathrm{Ag}=11,90 \%$, lo que lo clasifica como oro tipo electrum.

\section{Discusión}

\section{Química mineral y condiciones genéticas}

Los datos petromineralógicos y químicos muestran para el depósito Pilar una asociación de fases opacas de arsenopirita, pirrotita, pirita, calcopirita, esfalerita, galena y pentlandita, permitiendo establecer la paragénesis mineral asociada a la fase mineralizante para este depósito (pirita \pm pirrotita \pm arsenopirita $+\mathrm{Au}$ ).

Los procesos de exsolución, los cuales se evidencian mediante las inclusiones de pentlandita en la pirrotita, pueden estar asociados a la presencia de $\mathrm{Ni}$ en la estructura de esta fase mineral (Tabla 3) (Etschmann et al., 2004).
Xuexin (1984) menciona una diferencia entre la relación de Co: Ni en análisis realizados en piritas de origen hidrotermal y primarias en sedimentos originales, asociadas a depósitos minerales. Para los resultados de las piritas del depósito Pilar (Tabla 5), estas presentan valores de $\mathrm{Co} / \mathrm{Ni}$ menores a 1 ( 0 hasta 0,83 wt. \%) que corresponden a pirita primaria asociada a sedimentos originales, y pirita de origen hidrotermal con relación entre $2-3 \mathrm{de} \mathrm{Co} / \mathrm{Ni}(3 \mathrm{wt}$. \%).

Vaughan y Craig (1997) sugieren que las concentraciones de $\mathrm{Zn}$ en la esfalerita pueden estar relacionadas con la formación de pirita y/o pirrotita asociada a la mineralización principal, donde para estos autores los valores de $\mathrm{Zn}$ entre 61 y 63 wt. \% están asociadas a la formación de pirita, y los valores de $\mathrm{Zn}$ entre 51 y 58 wt. \%, están asociadas a la paragénesis pirita + pirrotita. Los valores de $\mathrm{Zn}$ en esfalerita para el depósito Pilar (Tabla 7), se encuentran entre 56,31 a 62,57 wt. $\%$, en este caso la esfalerita está relacionada a la paragénesis pirita + pirrotita asociada a la mineralización principal.

Tabla 7. Resultados de química mineral para esfalerita (wt. \%), recalculados en átomos por fórmula unitaria (afu) y porcentaje atómico (at. \%).

\begin{tabular}{|c|c|c|c|c|c|c|c|c|c|c|c|c|c|c|c|c|c|}
\hline \multirow{2}{*}{$\begin{array}{c}\begin{array}{c}\text { No. } \\
\text { Muestra }\end{array} \\
\begin{array}{c}\text { No. } \\
\text { Punto }\end{array}\end{array}$} & \multirow{2}{*}{$\begin{array}{c}\text { PL10A } \\
4 \text { _18 }\end{array}$} & \multirow{2}{*}{$\begin{array}{c}\text { PL10A } \\
\text { 4_20 }\end{array}$} & \multirow{2}{*}{$\begin{array}{c}\text { PL7B } \\
5 \_13\end{array}$} & \multirow{2}{*}{$\begin{array}{c}\text { PL10A } \\
4 \_19\end{array}$} & \multicolumn{2}{|c|}{ PL15B } & \multicolumn{5}{|c|}{ PL10A } & \multicolumn{6}{|c|}{ PL17C } \\
\hline & & & & & 5_9 & 5_8 & $10 \_1$ & $9 \_8$ & 1_27 & 9_6 & 2_25 & 3_14 & 3_10 & 3_13 & 3_12 & $2 \_5$ & 1_1 \\
\hline \multicolumn{18}{|l|}{ wt. \% } \\
\hline As & 0,00 & 0,00 & 0,00 & 0,00 & 0,00 & 0,00 & 0,00 & 0,00 & 0,00 & 0,00 & 0,00 & 0,00 & 0,00 & 0,00 & 0,00 & 0,00 & 0,00 \\
\hline $\mathrm{Zn}$ & 60,78 & 58,48 & 60,73 & 60,53 & 62,57 & 61,70 & 59,55 & 58,36 & 57,88 & 59,10 & 56,31 & 60,31 & 60,21 & 59,46 & 60,76 & 61,20 & 59,02 \\
\hline $\mathrm{Se}$ & 0,03 & 0,032 & 0,00 & 0,00 & 0,00 & 0,02 & 0,03 & 0,03 & 0,05 & 0,02 & 0,08 & 0,113 & 0,06 & 0,00 & 0,00 & 0,00 & 0,00 \\
\hline S & 32,66 & 32,57 & 32,52 & 32,51 & 32,33 & 32,27 & 32,26 & 32,25 & 32,23 & 32,20 & 31,37 & 31,19 & 31,15 & 30,92 & 30,70 & 30,61 & 30,42 \\
\hline $\mathrm{Pb}$ & 0,02 & 0,12 & 0,09 & 0,17 & 0,07 & 0,15 & 0,21 & 0,06 & 0,05 & 0,10 & 0,25 & 0,12 & 0,06 & 0,17 & 0,15 & 0,05 & 0,08 \\
\hline $\mathrm{Bi}$ & 0,11 & 0,00 & 0,00 & 0,00 & 0,00 & 0,00 & 0,00 & 0,00 & 0,00 & 0,00 & 0,00 & 0,00 & 0,00 & 0,05 & 0,09 & 0,00 & 0,00 \\
\hline $\mathrm{Cd}$ & 0,15 & 0,18 & 0,03 & 0,13 & 0,09 & 0,07 & 0,14 & 0,18 & 0,14 & 0,16 & 0,15 & 0,08 & 0,05 & 0,06 & 0,05 & 0,05 & 0,16 \\
\hline $\mathrm{Fe}$ & 5,91 & 6,05 & 5,76 & 5,66 & 6,26 & 6,54 & 5,83 & 6,25 & 6,16 & 6,21 & 6,01 & 5,97 & 5,73 & 5,79 & 5,69 & 5,79 & 5,75 \\
\hline $\mathrm{Cu}$ & 0,00 & 0,00 & 0,03 & 0,02 & 0,00 & 0,00 & 0,02 & 0,00 & 0,00 & 0,05 & 0,07 & 0,00 & 0,00 & 0,00 & 0,01 & 0,01 & 0,03 \\
\hline $\mathrm{Ni}$ & 0,03 & 0,01 & 0,00 & 0,00 & 0,00 & 0,02 & 0,00 & 0,00 & 0,01 & 0,00 & 0,00 & 0,01 & 0,02 & 0,00 & 0,00 & 0,02 & 0,02 \\
\hline Mo & 0,17 & 0,16 & 0,14 & 0,08 & 0,16 & 0,16 & 0,19 & 0,11 & 0,11 & 0,15 & 0,21 & 0,16 & 0,13 & 0,12 & 0,12 & 0,08 & 0,16 \\
\hline $\mathrm{Au}$ & 0,00 & 0,00 & 0,00 & 0,00 & 0,00 & 0,00 & 0,00 & 0,00 & 0,00 & 0,00 & 0,00 & 0,00 & 0,00 & 0,04 & 0,00 & 0,00 & 0,00 \\
\hline $\mathrm{Ag}$ & 0,00 & 0,00 & 0,01 & 0,01 & 0,00 & 0,00 & 0,01 & 0,00 & 0,01 & 0,00 & 0,01 & 0,00 & 0,03 & 0,01 & 0,00 & 0,00 & 0,00 \\
\hline Total & 99,89 & 97,62 & 99,32 & 99,09 & 101,48 & 100,94 & 98,25 & 97,26 & 96,63 & 97,99 & 94,49 & 97,96 & 97,45 & 96,62 & 97,57 & 97,82 & 95,65 \\
\hline \multicolumn{18}{|c|}{ Átomos por fórmula unitaria } \\
\hline S & 1,019 & 1,02 & 1,01 & 1,01 & 1,00 & 1,01 & 1,01 & 1,01 & 1,00 & 1,00 & 0,98 & 0,97 & 0,97 & 0,96 & 0,96 & 0,96 & 0,95 \\
\hline $\mathrm{Fe}$ & 0,10 & 0,11 & 0,10 & 0,10 & 0,11 & 0,11 & 0,10 & 0,11 & 0,11 & 0,11 & 0,11 & 0,11 & 0,10 & 0,10 & 0,10 & 0,10 & 0,10 \\
\hline $\mathrm{Zn}$ & 0,71 & 0,68 & 0,71 & 0,70 & 0,73 & 0,72 & 0,69 & 0,68 & 0,68 & 0,69 & 0,66 & 0,71 & 0,70 & 0,69 & 0,71 & 0,72 & 0,69 \\
\hline \multicolumn{18}{|c|}{ Porcentaje atómico } \\
\hline$\% \mathrm{~S}$ & 55,47 & 56,15 & 55,46 & 55,59 & 54,41 & 54,52 & 55,65 & 55,84 & 56,07 & 55,56 & 56,05 & 54,48 & 54,61 & 54,65 & 54,07 & 53,78 & 54,44 \\
\hline$\% \mathrm{Zn}$ & 38,76 & 37,86 & 38,89 & 38,86 & 39,54 & 39,14 & 38,57 & 37,95 & 37,81 & 38,29 & 37,78 & 39,54 & 39,63 & 39,47 & 40,18 & 40,38 & 39,66 \\
\hline
\end{tabular}


La presencia de galena asociada a algunas venas y a sulfuros también puede indicar que esta se formó al aumentar la temperatura, y que estaría relacionada al proceso hidrotermal asociado a la mineralización (Kant et al., 2012).

\section{Geotermometría de sulfuros}

La arsenopirita por ser un mineral refractario y por encontrarse de forma abundante en el depósito, fue utilizada para cálculos de temperatura. El método es basado en la composición química de la arsenopirita en paragénesis con otras fases minerales como pirrotita y pirita.
Los valores de porcentaje atómico (at. \%) de As en los cristales de arsenopirita corresponden a la paragénesis con pirrotita + pirita \pm Au y varían de 31,026 a 32,799; de acuerdo con el diagrama de Kretschmar y Scott (1976), estos valores indican que la temperatura de formación de la arsenopirita se encuentra en el intervalo de $363^{\circ} \mathrm{C}$ hasta $471^{\circ} \mathrm{C}$ (Figura 7). Comparado con el termómetro de Clark (1960) está paragénesis puede alcanzar un máximo de estabilidad en temperaturas de $491^{\circ} \mathrm{C}$ (Tabla 8).

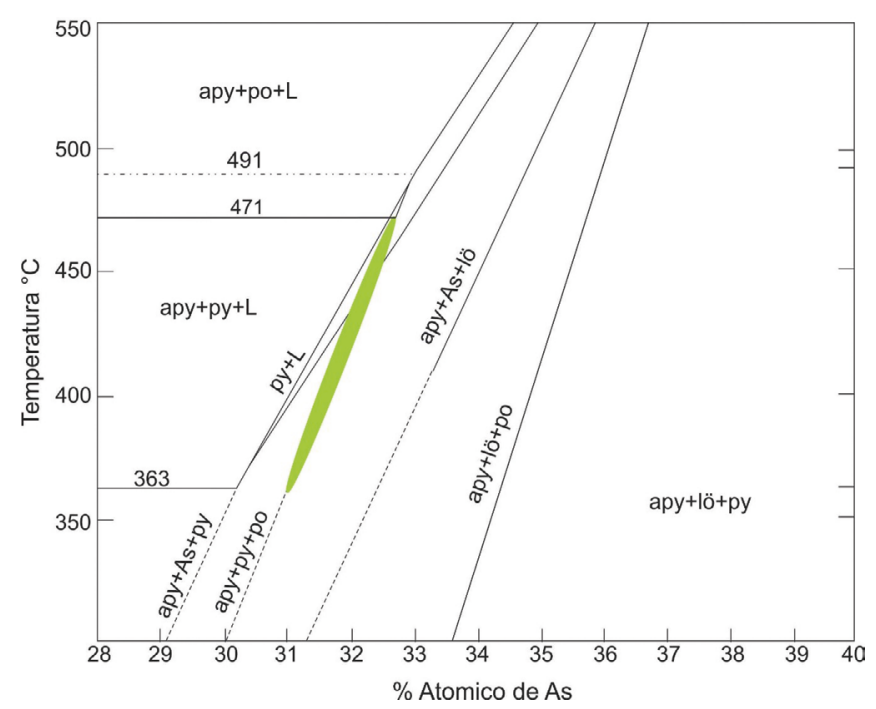

Figura 7. Concentración atómica de As aplicando geotermómetro en el diagrama de Kretschmar y Scott (1976) para arsenopirita (Apy), pirita (Py) y pirrotita (Po).

Tabla 8. Composición química, clasificación y temperatura de formación de arsenopiritas \pm pirita \pm pirrotita \pm oro.

\begin{tabular}{ccccccc}
\hline & & \multicolumn{3}{c}{ Composición Arsenopirita \% } & Temp. & Paragénesis \\
\cline { 3 - 5 } No. Muestra & No. Punto & \multicolumn{3}{c}{ Atómico } & As & \\
\cline { 2 - 5 } & & S & Fe & As & \\
\hline PL6A1 & $2 \_6$ & 36,55 & 32,41 & 31,02 & 363 & Asp+Po \\
PL6A1 & $3 \_11$ & 34,84 & 33,32 & 31,83 & 412,50 & Asp+Po \\
PL6A1 & $7 \_30$ & 35,13 & 32,83 & 32,03 & 425 & Asp+Po \\
PL6A1 & $7 \_29$ & 34,74 & 32,93 & 32,32 & 437,50 & Asp+Po+py \\
PL6A1 & $7 \_27$ & 34,25 & 32,95 & 32,79 & 475 & Asp+Po \\
PL6A1 & 3_8 & 34,47 & 32,51 & 33,01 & 485 & Asp+Po \\
PL6A & $7 \_11$ & 35,14 & 33,18 & 31,66 & 400 & Asp+Po+Au \\
PL6A & $1 \_3$ & 34,39 & 33,77 & 31,83 & 412,50 & Asp+Po \\
PL6A & $2 \_4$ & 34,69 & 32,89 & 32,41 & 450 & Asp+Po+py \\
PL4A & $9 \_58$ & 35,41 & 32,97 & 31,61 & 400 & Asp+Po \\
PL4A & 3_19 & 34,72 & 33,27 & 31,99 & 420 & Asp+Po \\
PL4A & $9 \_57$ & 34,51 & 33,46 & 32,01 & 425 & Asp+Po+Au \\
PL17C & 6_20 & 33,53 & 33,69 & 32,76 & 468,75 & Asp+Po \\
PL10A & $7 \_11$ & 33,98 & 33,47 & 32,544 & 457,50 & Asp+Po+py \\
\hline
\end{tabular}




\section{Conclusiones}

El depósito de oro Pilar está relacionado principalmente al BIF, el cual ha sido fuertemente sulfatado con pirita \pm pirrotita \pm arsenopirita $+\mathrm{Au}, \mathrm{y}$ de manera subordinada a las rocas máficas, ultramáficas, metasedimentarias y meta-volcanoclásticas. Los sulfuros ocurren diseminados $\mathrm{y} / \mathrm{o}$ en venas en las diferentes litologías, siendo la pirrotita el más abundante y la arsenopirita el principal sulfuro asociado a la fase mineralizada aurífera.

Las rocas encajantes asociadas al depósito Pilar se caracterizan por halos de alteración (distal, intermedio y proximal) que se desarrollaron sobre condiciones de facies esquistos verdes, donde estos fluidos generadores de la alteración fueron enriquecidos con $\mathrm{H}_{2} \mathrm{O}, \mathrm{SiO}_{2}, \mathrm{Fe}, \mathrm{S}$ y As, y ascendieron por conductos generados en un régimen de deformación dúctil-frágil en una zona de cizallamiento regional NE-SW (RíosGuerrero, 2016). La principal zona de alteración es denominada como zona de alteración proximal y es representada por la presencia de arsenopirita, pirrotita y en algunas ocasiones pirita en las diferentes litologías, y acompañada por oro en el BIF (Ríos-Guerrero, 2016). Los valores de oro registrados por la química mineral en la arsenopirita son interpretados como procesos de absorción química asociados a la interacción con fluidos hidrotermales en aquellas áreas enriquecidos en As e incorporado a las soluciones sólidas metaestables, lo que es común en este tipo de depósitos.

La relación de elementos como $\mathrm{Zn}, \mathrm{Ni}$, Co y $\mathrm{Sb}$ en depósitos minerales puede mostrar indicadores genéticos, y que se han visto reflejados en las variaciones composicionales de minerales como arsenopirita, pirita y esfalerita en el depósito Pilar. Estos han evidenciado condiciones químicas de los fluidos durante el evento hidrotermal y la relación con la paragénesis de mineralización principal. De esta forma, los sulfuros descritos anteriormente se han formado en condiciones químicas y temperaturas similares, que son asociadas a la formación de la mineralización de oro en el depósito Pilar.

Los procesos hidrotermales asociados con la formación de la mineralización según la paragénesis de los sulfuros (pirita \pm pirrotita \pm arsenopirita $+\mathrm{Au}$ ) revelan un equilibrio químico en el intervalo de temperatura entre $363^{\circ} \mathrm{C}$ hasta $471^{\circ} \mathrm{C}$.

De acuerdo con las evidencias citadas anteriormente, puede indicarse que el depósito de oro Pilar, presenta características metalogénicas comparables con otros depósitos de tipo oro orogénico.

\section{Agradecimientos}

Especial agradecimiento al Programa de posgrado en Geociencias de la Universidade Federal do Amazonas (UFAM), por el apoyo técnico, económico y científico, a través del proyecto de maestría titulado "Metalogêneses do deposito aurífero Pilar, Santa Bárbara, $M G$ ".

\section{Referencias}

Alkmim, F.F.; Marshak, S. (1998). Transamazonian orogeny in the Southern São Francisco craton region, Minas Gerais, Brazil: evidence for Paleoproterozoic collision and collapse in the Quadrilátero Ferrífero. Precambrian Research, 90(1-2), 29-58. https://doi.org/10.1016/S03019268(98)00032-1

Almeida, F.F.; Hasui, Y. (1984). O Pré-Cambriano do Brasil. Edgar Blücher Ltda.

Baltazar, O.F.; Zucchetti, M. (2007). Lithofacies associations and structural evolution of the Archean Rio das Velhas greenstone belt, Quadrilátero Ferrífero, Brazil: A review of the setting of gold deposits. Ore Geology Reviews, 32(3-4), 471-499. https://doi.org/10.1016/j. oregeorev.2005.03.021

Boyle, R.; Jonasson, I.R. (1973). The geochemistry of arsenic and its use as an indicator element in geochemical prospecting. Journal of Geochemical Exploration, 2(3), 251-296. https:// doi.org/10.1016/0375-6742(73)90003-4

Clark, L.A. (1960). The Fe-As-S System-Phase relations and applications. Economic Geology, 55(7), 1345-1381. https://doi.org/10.2113/ gsecongeo.55.7.1345

Eilu, P.; Groves, D.I. (2001). Primary alteration and geochemical dispersion haloes of Archaean orogenic gold deposits in the Yilgarn Craton: the pre-weathering scenario. Geochemistry: Exploration, Environment, Analysis, 1(3), 183200. https://doi.org/10.1144/geochem.1.3.183 
Etschmann, B.; Pring, A.; Putnis, A.; Grguric, B.A.; Studer, A. (2004). A kinetic study of the exsolution of pentlandite $(\mathrm{Ni}, \mathrm{Fe})_{9} \mathrm{~S}_{8}$ from the monosulfide solid solution (Fe, Ni)S. American Mineralogist, 89(1), 39-50. https://doi.org/10.2138/am-20040106

Farina, F.; Albert, C.; Martínez-Dopico, C.; AguilarGil, C.; Moreira, H.; Hippertt, J.P.; Cutts, K.; Alkmim, F.F.; Lana, C. (2016). The ArcheanPaleoproterozoic evolution of the Quadrilátero Ferrífero (Brasil): Current models and open questions. Journal of South American Earth Scienses, 68, 4-21. https://doi.org/10.1016/j. jsames.2015.10.015

Groves, D.; Goldfarb, R.; Gebre-Mariam, M.; Hagemann, S.; Robert, F. (1998). Orogenic gold deposits: a proposed classification in the context of their crustal distribution and relationship to other gold deposit types. Ore Geology Reviews, 13(1-5), 7-27. https://doi.org/10.1016/S01691368(97)00012-7

Kant, W.; Warmada, I.; Idrus, A.; Setijadji, L.D.; Watanabe, K. (2012). Ore mineralogy and mineral chemistry of pyrite, galena, and sphalerite at Soripesa Prospect area, Sumbawa island, Indonesia. Journal of Applied Geology, 4(1), 1-14. https://doi.org/10.22146/jag.7191

Kretschmar, U.; Scott, S.D. (1976). Phase relations involving arsenopyrite in the system Fe-As-S and their application. The Canadian Mineralogist, 14(3), 364-386.

Le Vaillant, M.; Barnes, S.J.; Fiorentini, M.L.; Miller, J.; McCuaig, T.C.; Muccilli, P. (2015). A hydrothermal Ni-As-PGE geochemical halo around the Miitel komatiite-hosted nickel sulfide deposit, Yilgarn Craton, Western Australia. Economic Geology, 110(2), 505-530. https://doi. org/10.2113/econgeo.110.2.505

Marshak, S.; Alkmim, F.F.; Jordt-Evangelista, H. (1992). Proterozoic crustal extension and the generation of dome-and-keel structure in an Archaean granite-greenstone terrane. Nature, 357, 491-493. https://doi.org/10.1038/357491a0

Noce, C.M.; Machado, N. (1998). Eventos de cisalhamento e mineralização aurífera na região nordeste do Quadrilátero Ferrífero: Considerações baseadas em análises $\mathrm{U}-\mathrm{Pb}$ de rutilo e titanita. Geonomos, 6(1), 21-24. https://doi.org/10.18285/ geonomos.v6i1.161

Passos, R.V. (1999). Caracterização da geometria de zonas de alteração hidrotermal - Estudo de caso no depósito aurífero de Brumal, Quadrilátero Ferrífero/Minas Gerais. Tese de Mestrado, Universidade Estadual de Campinas, Brasil.

Ríos-Guerrero, J. (2016). Metalogênese do depósito aurífero Pilar, Santa Bárbara, MG. Tese de Mestrado, Universidade Federal do Amazonas, Brasil.

Schorscher, H.D. (1978). Komatiitos na estrutura Greenstone Belt Série Rio das Velhas, Quadrilátero Ferrífero, Minas Gerais, Brasil. Congresso Brasileiro de Geologia, Recife, Brasil.

Silva, L.C. (2007). Depósito Pilar: Contexto geológico, alteração hidrotermal e mineralização aurífera. Tese de Mestrado, Universidade Federal de Minas Gerais, Brasil.

Teixeira, W. (1985). A evolução geotectônica da porção meridional do Cratón do São Francisco, com base em interpretações geocronológicas. Tese de Doutoramento, Universidade de São Paulo, São Paulo, Brasil.

Vaughan, D.; Craig, J. (1997). Sulfide ore mineral stabilities, morphologies, and intergrowth textures. In: H.L. Barnes (ed). Geochemistry of Hydrothermal Ore Deposits (pp. 367-434). 3rd edition. Wiley-Interscience.

Vieira, F.W.R. (1991). Textures and processes of hydrothermal alteration and mineralization in the Nova Lima Group, Minas Gerais, Brazil. In: E.A. Ladeira (ed.). Brazil gold '91, the economics, geology, geochemistry and genesis of gold deposits (pp. 319-325). Balkema, Rotterdam.

Xuexin, S. (1984). Minor elements and ore genesis of the Fankou lead-zinc deposit, China. Mineralium Deposita, 19(2), 95-104. https://doi.org/10.1007/ BF00204667

Fecha de recibido: 08 de julio de 2019

Fecha de aprobado: 21 de octubre de 2020 